\title{
A metodologia historiográfica na pesquisa em administração: uma discussão acerca de princípios e de sua aplicabilidade no brasil contemporâneo
}

\section{The historical methodology in the research in administration: a debate concerning principles and its applicability in Brazil}

Octavio Penna Pieranti

\begin{abstract}
Resumo
A adaptação da historiografia como metodologia para pesquisa em Administração, ainda pouco comum, ampara-se em princípios específicos ligados não só à sua própria natureza, como a essa área de conhecimento. Nem sempre é simples a aplicação desses princípios em pesquisas contemporâneas, devido a características únicas da realidade brasileira. Este artigo tem por objetivo discutir os princípios naturais à metodologia historiográfica, tal como compreendida na contemporaneidade, e a possibilidade de aplicação desses princípios no campo da Administração no Brasil. Os pilares debatidos são, entre outros, a ênfase na interpretação das estruturas, a aceitação de perspectivas múltiplas, a singularidade dos eventos e a ligação entre História e passado. Entram em discussão, também, as fontes para pesquisas de cunho histórico e sua disponibilidade no Brasil. 0 debate travado é exemplificado por duas pesquisas realizadas na última década no âmbito da Administração. Evidenciam-se problemas para a aplicação dessa metodologia no contexto brasileiro, tais como a fragilidade das estruturas políticas nacionais e as falhas de documentação de textos oficiais.
\end{abstract}

Palavras-chave: Método Histórico, Historiografia, Pesquisa

Abstract

The adaptation of historiography as methodology for research in Administration, although uncommon, is supported on specific principles related to its proper nature and to this area of knowledge. The application of these principles in research isn't always simple due to specific characteristics of the Brazilian reality. The objective of this study is to discuss the natural principles of historiography, as understood in the present, and the possibility of application of these principles in the field of the Administration in Brazil. The debated pillars are, among others, the emphasis on the interpretation of the structures, the acceptance of multiple perspectives, the singularity of the events and the links between History and the past. The sources for historical researches and their availability in Brazil are also debated. Two researches made in the last decade in the field of administration are presented as examples of the historical method. Problems on the application of this methodology in the Brazilian context, such as the fragility of the political structures in the country and the precarious documentation of official texts, are evidenced.

Key Words: Historical Method, Historiography, Research

\footnotetext{
Doutorando em Administração pela Escola Brasileira de Administração Pública e de Empresas da Fundação Getulio Vargas (EBAPE/FGV), Mestre em Administração Pública - EBAPE/FGV. Endereço: Praia de Botafogo, 190 - 5 a andar. Rio de Janeiro-RJ. Brasil E-mail: octavio@fgvmail.br

Artigo submetido em junho de 2006 e aceito em janeiro de 2007
} 


\section{Introdução}

Temas estudados no campo da Administração encontram, não raro, explicação em eventos ocorridos no passado e em estruturas consolidadas ao longo do tempo. Por mais que o estudo não se limite a essas origens, a História passa a ser, nesses casos, campo de cujo conhecimento o pesquisador não pode abdicar.

Já que na História podem estar respostas e considerações para assuntos estudados na Administração, cabe refletir a integração entre essas duas áreas. A metodologia historiográfica pode ser aplicada à pesquisa em Administração, de acordo com determinados princípios que proporcionam o rigor científico necessário a uma dada investigação. $\mathrm{O}$ debate acerca desses princípios merece, no contexto brasileiro, uma reflexão pormenorizada, graças a especificidades incomuns a outros países, discutidas adiante.

O objetivo deste artigo é discutir os princípios da metodologia historiográfica e sua aplicabilidade no campo da Administração no Brasil contemporâneo. Cabe uma ressalva para evitar ambigüidades: ao falar em Brasil contemporâneo não se está fazendo uma limitação temporal dos temas pesquisados; a referência temporal nessa expressão diz respeito à época de desenvolvimento da pesquisa. Assim, serão discutidos os princípios da metodologia historiográfica em pesquisas desenvolvidas no presente, independentemente do período em que ocorreram os eventos estudados.

Na primeira seção deste artigo, serão apresentados os princípios dessa metodologia na contemporaneidade e sua relação com a pesquisa em Administração. A seguir, serão debatidas as fontes históricas utilizadas em pesquisas no campo da Administração. Em um terceiro momento, a discussão envolverá especificamente a realidade brasileira, por meio da apresentação de duas pesquisas expostas como exemplo do emprego da metodologia historiográfica em estudos no campo da Administração.

\section{Princípios da historiografia e a pesquisa em administração}

A compreensão e a aceitação da historiografia como metodologia válida para a pesquisa em Administração passa, em primeiro plano, por uma crença decisiva: o reconhecimento de que a História é determinante para explicar os acontecimentos e as estruturas existentes em qualquer sociedade. Assim, a História, como frisa Firat (1987), é, sob essa perspectiva, central para o entendimento da humanidade.

Aceita a História como central à compreensão de acontecimentos e estruturas, torna-se natural sua ligação com a Administração. Como aponta Pieranti (2005, p. 8):

"Mais que instrumento para a investigação, a História é disciplina e entendimento dos quais deriva forma específica de observação dos fatos. Entender a História como linha mestra e explicativa dos acontecimentos não significa sobrepô-la à Administração e seus tradicionais mecanismos de coleta de dados e análise dos mesmos; significa, sim, compreender a interpretação com base histórica como um dos caminhos possíveis à investigação em Administração, notadamente no que se refere a problemas de pesquisa no âmbito público. Significa, enfim, acreditar que políticas públicas e relações de poder, por exemplo, têm fortes bases históricas e que, portanto, podem ser explicadas por métodos de pesquisa ligados a essa disciplina."

A "forma específica de observação dos fatos" a que alude Pieranti (2005) está ligada à época analisada, ou seja, depende de condicionantes históricas em transformação permanente. Firat (1987) destaca que, independentemente de qualquer corrente político-filosófica, há uma crença comum na singularidade dos eventos históricos. De acordo com os autores, historiadores e pesquisadores que fazem uso da metodologia historiográfica não discordam de que a época e o contexto em que ocorre dado evento estão intimamente ligados com suas causas, não podendo, pois, ser reproduzidos ou generalizados. Os eventos históricos devem ser tratados como únicos, conforme suas especificidades. Smith (1991, p. 5, tradução livre), ao analisar esse ponto, é taxativo: "normalmente fica explícito que as informações não podem ser compreendidas, se não forem relacionadas ao seu contexto". 
Para a pesquisa em Administração é crucial a implicação dessa constatação. Decisões no âmbito empresarial ou formulações de políticas públicas, por exemplo, devem ser analisadas de acordo com seu contexto histórico, em conformidade com condicionantes políticas, econômicas, sociais, geográficas e outras. Análises descontextualizadas perdem sua relevância, na medida em que se tornam pouco factíveis ou possivelmente descoladas da realidade.

A análise de condicionantes está também relacionada a uma interpretação e a um reconhecimento de múltiplas perspectivas de observação. Tuchman (2003, p. 225, tradução livre) lembra que a pesquisa de cunho histórico está ligada a uma visão específica, que será determinante para as conclusões da investigação: "Seja realizada por cientistas sociais, seja por historiadores, a pesquisa histórica requer um ponto de vista. Um ponto de vista necessariamente inclui uma perspectiva de interpretação que implicitamente contém uma noção de "sentido de história"”.

Cabe salientar algumas observações a respeito das exposições de Tuchman (2003) e Firat (1987), complementadas pelo debate acerca das fontes históricas que será realizado na próxima seção deste artigo. A primeira é a constatação de que a perspectiva do observador ou do pesquisador afirma-se como a base do processo de investigação, anterior mesmo à análise propriamente dita. Ou seja: a perspectiva do autor está intrinsecamente ligada a seu modo de ver e expor a História, sendo determinante, em parte, do seu relato e das interpretações daí decorrentes.

Uma segunda observação é o permanente contato entre passado e presente em pesquisas de cunho histórico. Por mais que seja plenamente aceita a necessidade de contextualização da matéria pesquisada, forçando um distanciamento entre presente e passado, isso nunca é feito de forma absoluta e natural. Não se pode negar a natureza humana do pesquisador e, conseqüentemente, seu conjunto de referências comuns ao tempo presente, não raro distante da época e do local estudados. $\mathrm{O}$ embate entre o isolamento do pesquisador em relação ao tempo presente (ou, em pesquisas que cheguem até a contemporaneidade, a relativização das condicionantes nas diferentes etapas do estudo) e o uso, ainda que involuntário, de conjuntos de referências contemporâneos é constante e mesmo necessário. Assim, deve prevalecer o reconhecimento das limitações da historiografia, implicando na aceitação dos resultados obtidos como um encaminhamento, dentre outros possíveis, da pesquisa proposta.

A historiografia está obrigatoriamente ligada ao passado. Mesmo que busque uma análise de acontecimentos e estruturas contemporâneos, suas fontes remetem ao passado. Smith (1991) reforça que o termo "histórico" sugere automaticamente fatos passados ou seqüências temporais, sendo que tudo que pode ser observado já era passado quando foi inicialmente analisado ou terminou quando o observador decidiu concluir sua investigação. É impossível, assim, uma análise contemporânea do tempo presente, uma vez que esse, quando discutido, já será passado.

As limitações expostas ensejam uma breve discussão acerca da validade do uso da historiografia como metodologia para a pesquisa em Administração. Jacobs (2001) destaca três justificativas para a realização de pesquisas por meio do uso da metodologia historiográfica. Para ele, uma abordagem histórica permite ao pesquisador estabelecer trajetórias e desenhos dentro dos quais é possível observar uma concatenação entre os diferentes acontecimentos. Isso evita, por exemplo, que se analisem políticas de forma isolada, sem que haja interligação entre elas e outras áreas.

O reconhecimento dessa interligação é central para a segunda justificativa do autor, para quem a historiografia encoraja a exploração de fatos de uma maneira holística, ao levar em consideração, por exemplo, a influência de ideologias e a interação entre a matéria estudada e fatores econômicos e culturais. A aceitação de uma realidade multifacetada (e de fragmentos dela) implica em uma contextualização pormenorizada, em um esforço contínuo de se desnudar, ao máximo, a realidade em seus diferentes âmbitos, mesmo que essa análise seja orientada sempre em conformidade com uma perspectiva específica.

Por fim, o autor inverte a lógica que envolve a perspectiva individualizada na metodologia historiográfica. Se, para alguns, ela pode ser entendida como prejudicial à precisão da pesquisa justamente por valer-se de 
orientações pessoais alheias ao estudo propriamente dito, pode, também, ser encarada de forma positiva, já que permite análises eminentemente críticas e baseadas em informações diversificadas, sendo um diferencial para o desenvolvimento de pesquisas acadêmicas.

Os princípios anteriormente expostos decorrem de uma ruptura na concepção da História. Até a década de 1920, prevalecia, no tocante à historiografia, o paradigma denominado por Curado (2001) de História Tradicional. Baseava-se, segundo a autora, em documentos oficiais e escritos, material para uma análise essencialmente do âmbito político, centrada em acontecimentos reconhecidos como importantes e em personagens de destaque, logo um entendimento voltado às ações individuais. A História era encarada, então, como uma narrativa dos acontecimentos, sendo que o historiador seria responsável apenas por apresentar os fatos, valendo-se de uma narrativa objetiva e imparcial.

Um dos momentos simbólicos da ruptura com a visão tradicional da História foi a publicação, na França, da revista Annales: économies, societés, civilisations. Reflexo de debates, a publicação consagrava a aceitação, nas reflexões acadêmicas, de interpretações diferenciadas, que já se delineavam ao longo dos anos anteriores. Para Firat (1987), afirmava-se, então, uma escola analítica e empírica da historiografia. Os historiadores franceses dispunham-se a entender o passado, buscando nele as relações causais para explicar os acontecimentos estudados. Para isso, como lembra Martins (2001, p. 153), repensavam as bases sobre as quais repousava a própria História:

"A história total de Lucien Febvre e Marc Bloch - fundadores da revista e posteriormente escola dos Annales (1929) - trouxe a proposta de uma disciplina histórica na qual o econômico e o social ocupam lugar central e as estruturas duráveis, os fenômenos de longa duração e os comportamentos coletivos são mais reais e determinantes do que os regimes políticos, as iniciativas individuais e os acidentes de conjuntura (cânones do pensamento da corrente precedente)."

Essa compreensão da História, de acordo com perspectivas ampliadas, dá ensejo à interpretação individualizada abordada anteriormente. Vale ressaltar, em conformidade com esse cenário, comentário de Vergara (2005), para quem essa interpretação está na base da historiografia na contemporaneidade. Não é suficiente à historiografia a análise das estruturas; é preciso que essas sejam interpretadas, de modo que não se repita uma simples narrativa dos acontecimentos, focada normalmente na ação individual dos personagens, como era comum na História Tradicional.

A mudança de visão ecoada pela revista Annales foi, como mencionado anteriormente, determinante para a compreensão da História no decorrer do século XX. Aos poucos, retirava-se de cena uma narrativa linear dos acontecimentos e, no mais das vezes, de cores oficiais, dando espaço a uma metodologia crítica. Por meio do desenvolvimento de métodos de análise voltados a dados históricos, os historiadores franceses tentavam trazer, nas palavras de Firat (1987, p. 435), "cientificidade e respeitabilidade para a História". Na verdade, inauguravam uma nova forma de observação da História, com foco na crítica e na interpretação, sem que dela se desprendesse um necessário rigor. Essa mudança na compreensão da História alimentaria correntes distintas ao longo do século XX, dentre as quais a hermenêutica, o materialismo histórico e o relativismo. Note-se que essas correntes não nasceram a partir da publicação de Annales, mas essa viria a estimular a análise sob distintas perspectivas.

Ainda que haja diferenças nítidas entre essas correntes, Curado (2001) busca reuni-las em torno da Nova História, termo em nítida contraposição à História Tradicional. De uma forma geral, todas as correntes reunidas sob esse epíteto têm como foco central as estruturas, propondo uma análise em múltiplas dimensões (econômica, política e cultural, por exemplo), de caráter não-oficial e multifacetado (colhendo argumentos e evidências históricas originadas nas mais distintas camadas sociais, a depender da pesquisa), com preocupação acerca tanto de movimentos coletivos, quanto de ações individuais, e baseada em distintas abordagens metodológicas. Assim, o manto da Nova História, por exemplo, atende as preocupações com as diferenças culturais, próprias do relativismo; com a influência da interpretação na narrativa dos acontecimentos e em sua relação com a realidade, comuns, de formas diferenciadas, à hermenêutica e ao materialismo histórico. Ainda 
que peque pela imprecisão, a reunião das distintas correntes no âmbito da Nova História permite um debate mais direcionado sobre os princípios que, de forma geral, marcam a historiografia contemporânea.

Antes que se proceda à próxima seção deste artigo, convém pontuar, de forma consolidada, o que foi exposto como princípios da pesquisa de cunho histórico voltada à Administração:

- A História explica acontecimentos e estruturas de uma dada sociedade;

- A pesquisa de cunho histórico tem como base o passado, mesmo que esse seja visto como raiz para a explicação do presente;

- Eventos históricos são singulares e intimamente ligados a contextos específicos, não podendo ter suas causas e conseqüências generalizadas;

- A pretensa realidade histórica varia em conformidade com a perspectiva de seus personagens e observadores, não havendo, portanto, uma única e absoluta realidade;

- Múltiplas perspectivas são aceitas, possibilitando a interligação entre áreas diversas do conhecimento;

- Estruturas são centrais à compreensão da sociedade, bem como interpretações e indícios em relação a elas em âmbitos diversos, como os político, econômico, social e cultural.

\section{As fontes em pesquisas de cunho histórico}

Se, por um lado, o paradigma mais freqüente na historiografia contemporânea reduziu a importância das ações individuais e valorizou as estruturas como unidades de análise duradouras, por outro ainda cabe ao indivíduo e ao relato individualizado a centralidade no processo de investigação. Por mais paradoxal que pareça a afirmação, o indivíduo está no cerne da análise das estruturas: é ele quem detém as informações (mesmo as oficiais) e as disponibiliza; é ele quem, entrevistado, reconta a história, de acordo com sua perspectiva; é ele quem investiga e estuda. Mesmo documentos oficiais e impessoais - leis, por exemplo - guardam uma carga de individualidade, já que refletem o comportamento de indivíduos específicos e o contexto que os envolve.

A pesquisa de cunho histórico, assim, está permanentemente às voltas com idiossincrasias, o que leva Tuchman (2003) a realçar a importância da confiabilidade das fontes e dos dados. Esse conceito é central à pesquisa, já que dados imprecisos ou mal trabalhados e fontes pouco confiáveis comprometem a relevância do estudo e o rigor dos resultados. Na mesma direção aponta Jacobs (2001), para quem cabe ao historiador e ao investigador que desenvolve pesquisas com esse cunho, com base em seu julgamento pessoal a respeito da confiabilidade das fontes históricas, selecionar o material a ser usado e as evidências disponíveis para a construção do relato. Tuchman (2003) ressalta, ainda, problemas comuns à metodologia historiográfica no tocante aos dados (principalmente os secundários) e fontes: artigos muito citados, por exemplo, ao invés de serem importantes, podem ser mencionados como uma interpretação errônea dos fatos; dados quantitativos podem esconder viés e ideologia próprios e não explicitados de quem os reuniu; informações arquivadas podem atender a taxonomias nem sempre claras a quem fizer uso delas.

Mesmo informações oficiais, provenientes de governos e empresas, podem suscitar dúvidas a respeito de sua confiabilidade. Pode-se atribuir, pelo menos, duas justificativas a essa afirmação. A primeira é a falta de interesse em tornar públicas determinadas informações por parte de governos e empresas. Especificamente no âmbito público, essa carência é minorada em alguns países que dispõem de legislação própria, tornando obrigatório o repasse de informações à sociedade. Essa possibilidade permitiu, por exemplo, que Moraes Neto e Silveira (1992) e Moraes Neto (1997) recontassem parte da história brasileira com base em documentos enviados à Inglaterra e aos Estados Unidos por seus respectivos corpos diplomáticos. Especificamente nos Estados Unidos, como relata Moraes Neto (1997), documentos oficiais tornam-se públicos passado um período de tempo fixo, variável conforme o nível de segurança das informações, estipulado pelo governo. Ao aludir ao Freedom of Information Act, pesquisadores passam a ter direito ao acesso a essas informações. No Brasil, o 
prazo para a liberação para consulta pública de documentos oficiais foi dilatado a partir da década de 1990. Além disso, os documentos considerados "ultra-secretos" não são mais obrigatoriamente liberados.

A segunda justificativa é a possibilidade de maquiagem, por parte de empresas e de governos, de dados que não lhes agradem. Deve-se confiar, por exemplo, em resultados, aparentemente positivos, de programas governamentais tidos publicamente como grandes fracassos? Ou como acreditar em balanços positivos de empresas oficiosamente tidas como em situação pré-falimentar ou de clubes de futebol brasileiros, mergulhados constantemente em graves crises financeiras? Às vezes, ainda, os dados não podem ser maquiados ou disponibilizados, porque simplesmente não foram reunidos de forma apropriada pelas empresas ou pelos órgãos públicos. Em seu estudo sobre política interna, Jacobs (2001, p. 132, tradução livre) frisa que documentos produzidos no âmbito da Administração Pública podem sofrer outro problema:

“(...) os documentos são escritos com um propósito específico voltado para a audiência desejada e isso é o fator que afeta de forma mais significante tanto a imagem, quanto a apresentação do material. Uma característica de documentos governamentais tanto no nível nacional, quanto no local é a sua assepsia. É improvável que eles reflitam desacordos e muito do que é escrito volta-se para a construção de uma imagem de construção linear, sistemática e racional da política."

Pairam sobre dados oficiais, dessa forma, dúvidas quanto a sua confiabilidade. Ao mesmo tempo em que as observações feitas anteriormente sugerem prudência no tratamento desses dados, demandam cuidados especiais com a propalada objetividade e com a isenção. Quando a confiabilidade dos dados não é plena, cabe ao investigador que faz uso da metodologia historiográfica apresentar as diferentes versões ou, ao menos, ressaltar possíveis imprecisões de seu estudo. Não pode, portanto, adotar a objetividade e a isenção como dogmas, ignorando o caráter relativo dos resultados de seu estudo e a obrigatória escolha de uma perspectiva para ele, o que é tido como natural pela metodologia historiográfica, conforme debatido anteriormente.

O problema torna-se mais complexo, quando o pesquisador alia as entrevistas, encaradas como fontes primárias, ao uso de documentos. Como defende Tuchman (2003), às vezes somente é possível discernir determinados significados ou conduzir análises históricas com base em um "informante com conhecimentos" (expressão do autor), ou seja, uma personagem que atingiu posição proeminente o suficiente para dispor de informações que não constam de fontes históricas outras, tais como documentos.

$\mathrm{Na}$ investigação de cunho histórico, as entrevistas têm normalmente, como base, a história oral, método que, a partir da segunda metade do século XX, foi consagrado para a realização de pesquisas contemporâneas, de acordo com Alberti (1989). A partir de entrevistas feitas com personagens centrais em diversas áreas da vida pública, elucidam-se versões sobre acontecimentos e interpretações sobre estruturas, culminando na caracterização dos depoimentos como fontes de informação para pesquisas variadas. As análises dos entrevistados são, em parte, subjetivas e dependentes das idiossincrasias dos depoentes, devendo necessariamente ser encaradas como fonte auxiliar no estudo. Por outro lado, a história oral caracteriza-se como alternativa tanto à pretensa objetividade dos documentos oficiais, quanto à indisponibilidade dos mesmos. Pode ser vista, portanto, como forma de contrabalançar a imprecisão, a aparente falta de conflitos, ou até mesmo a inexistência de versões oficiais, opondo interpretações múltiplas à suposta verdade única ou ao senso comum. Por mais que sejam subjetivos, os documentos advindos desse método são considerados fontes válidas.

Ferreira (1994) distingue duas linhas de trabalho, não totalmente independentes, para se lidar com a história oral. A primeira delas entende os depoimentos como alternativas para a complementação de dados históricos não disponíveis em documentos escritos, tendo, como focos centrais, políticas públicas, estudos acerca das elites e as formas de organização de determinados segmentos sociais. Já a segunda abordagem explora as representações e as formas como elas são compreendidas, privilegiando uma discussão acerca da relação entre memória e história.

Note-se a interdisciplinaridade que permeia a história oral. Pieranti (2005, p. 10) ressalta, por exemplo, seu vínculo com o jornalismo: "Não seria exagero dizer que esse método de pesquisa tem pontos de contato com a investigação jornalística. Também a ela são vitais os depoimentos de personagens que vivenciaram os 
acontecimentos em questão." O jornalismo especificamente marca a história oral desde suas origens. De acordo com Ferreira (1994), na década de 1940, o jornalista norte-americano Allan Nevins foi o responsável por um programa de entrevistas em que recuperava informações sobre a atuação das elites norte-americanas, embrião do que viria a ser o Columbia Oral History Office na década seguinte. Ademais, torna-se necessário o conhecimento de fundamentos de psicologia e eventualmente de sociologia para uma plena interpretação das entrevistas e, em todos os casos, o conhecimento da trajetória do entrevistado, bem como de sua área de atuação. Para fazer uso da metodologia historiográfica voltada à Administração, o investigador deve, por exemplo, compreender temas relativos às organizações e a políticas públicas, dependendo do conteúdo sobre o qual discorrerá o entrevistado.

Dentre os problemas inerentes à utilização da história oral, Jacobs (2001) destaca a distorção do relato, perigo natural a qualquer entrevista. Faz-se necessária uma ressalva: as diferenças de perspectiva, discutidas anteriormente, dizem respeito a modos diferentes de interpretar determinadas situações, ao passo que a distorção remete a mudanças no relato do acontecimento factual em si, por vezes misturando nele anseios e reflexões dos próprios entrevistados. Um dirigente de uma empresa, por exemplo, tende a minorar os problemas pelos quais sua gestão passou, enfatizando seus sucessos. O autor reforça que "os bons dias" funcionam como estratégia narrativa para alguns entrevistados, que têm por hábito idealizar o passado, como se ele somente guardasse aspectos positivos quando comparado ao presente. Obviamente nem sempre a distorção é feita de forma intencional pelo entrevistado. Por vezes, ele simplesmente não lembra as informações solicitadas ou, com o tempo, passou a confundi-las.

Para Curado (2001), por mais que documentos oficiais e entrevistas ofereçam subsídios para a pesquisa de cunho histórico, por si só essas fontes podem não ser suficientes. A autora lembra, por exemplo, a importância, para a pesquisa no campo da Administração de Empresas, de documentos administrativos, para fornecer evidências sobre o objeto estudado; livros de atas, que demonstram como as decisões foram tomadas; diários e livros de contabilidade, para explicar o uso dos recursos financeiros da empresa; relatórios anuais, que dão uma visão do conjunto das atividades da empresa; fichas de funcionários, capazes de delinear o perfil da mão-deobra e de reestruturações da empresa. Já Martins (2001) ressalta a importância de documentos outros, tais como manuscritos, álbuns de fotografias, obras de arte e monumentos. Já Pieranti (2005) destaca a possibilidade de uso de reportagens veiculadas pela imprensa nas mais diferentes mídias, principalmente em relação a temas contemporâneos ou que estejam em debate no momento em que a pesquisa for desenvolvida. Essas fontes, segundo o autor, tornam-se mais importantes, na medida em que o debate acadêmico nem sempre versa sobre acontecimentos ocorridos no passado recente.

Face à profusão de fontes históricas existentes e às diferenças inerentes à natureza delas, surge a necessidade de diversificação dos métodos para análise dos dados. Aos métodos mais comumente usados no tocante a esse tipo de pesquisa, como, por exemplo, as análises de conteúdo e de discurso, somam-se outros, tais como a análise estatística. Mahoney (2004) lista uma série de possibilidades para a utilização dessa análise, no âmbito das pesquisas de cunho histórico, com base em instrumentos que passam pela probabilidade, pela elaboração de tipologias apropriadas e pela validação de variáveis. Em sua proposta metodológica para a pesquisa de cunho histórico em Administração, Curado (2001) busca relacionar a pesquisa de dados secundários e as entrevistas com o que chama de tipologia de saber administrativo, construída previamente na primeira etapa da investigação.

A diversificação de métodos voltados a esse tipo de pesquisa não está no escopo deste trabalho, cujo enfoque central são os princípios naturais a esse tipo de investigação e não os métodos que a operacionalizam. Cabe, porém, ressaltá-la como importante para essas pesquisas; mesma qualificação merecendo a ampliação de fontes reconhecidas como válidas para esses estudos. Convém, agora, analisar a aplicabilidade, no Brasil contemporâneo, dos princípios que regem a pesquisa de cunho histórico no campo da Administração. 


\section{A Pesquisa de cunho histórico em administração no Brasil contemporâneo}

É farta a produção literária, no Brasil contemporâneo, que faz uso da historiografia para recontar a trajetória de personagens e estruturas. Por mais que essas estejam na base da investigação histórica, de acordo com os princípios segundo os quais a metodologia historiográfica é compreendida no presente, são as trajetórias de personagens as que mais têm chamado a atenção dos autores. Os exemplos, nesses casos, são variados e consolidados, como os que se encontram na forma de biografias (ou seja, trabalhos não acadêmicos). No campo da iniciativa privada, podem-se destacar biografias, por exemplo, de empresários diversos, como Roberto Marinho, dono das Organizações Globo (BIAL, 2004), Assis Chateaubriand, dono dos Diários Associados (MORAIS, 1994) e Mauá, dono de diversos empreendimentos no Brasil no século XIX (CALDEIRA, 1995). No âmbito público, entre os personagens biografados estão o senador Antônio Carlos Magalhães (GOMES, 2001), o ex-ministro das Comunicações Sérgio Motta (PRATA; BEIRÃO; TOMIOKA, 1999) e o marechal e ex-ministro da Guerra Henrique Lott (WILLIAM, 2006).

Apesar de análises de cunho histórico serem freqüentes na literatura brasileira, no âmbito da pesquisa acadêmica em Administração - e, conseqüentemente, com o rigor metodológico apropriado -, a investigação feita por meio da historiografia não é comum. Para exemplificar a discussão travada neste artigo, foram escolhidos dois estudos recentes, realizados no âmbito da Administração, que têm, como ponto de contato, a utilização da historiografia como metodologia de pesquisa. Os dois estudos não foram escolhidos apenas por essa semelhança, mas também por suas diferenças: os dois autores discutem temas distintos, separados na cronologia por décadas, e fazem uso de fontes diversas, sendo obrigados a utilizar-se, portanto, de distintas estratégias de investigação. Cabe ressaltar que o interesse pelos resultados das pesquisas, aqui, é secundário, sendo central a compreensão da metodologia utilizada e das estratégias de investigação a ela inerentes.

A primeira pesquisa em questão é a feita por Martins (2001), cujo objetivo é o entendimento do fenômeno de Canudos - ou seja, a comunidade de Belo Monte, chefiada por Antônio Conselheiro no século XIX - na perspectiva dos estudos organizacionais. A administração dessa comunidade, se não se orientava por conceitos teóricos e estudos prévios, delineava-se de acordo com a capacidade de improvisação de seu líder e seu conhecimento prático sobre gerência. Permeiam, portanto, o estudo desenvolvido pelo autor, conceitos como divisão do trabalho, poder local e organização social, inserindo a temática, graças ao modo com que foi tratada, no campo da Administração.

Dado o tempo que separou os acontecimentos do início da pesquisa do autor, muitas informações haviam se perdido. Entrevistas, por sua vez, teriam que ser feitas, na maioria das vezes, com especialistas que não viveram os acontecimentos, visto que os sobreviventes da epopéia de Canudos já haviam falecido. A utilização da história oral seria limitada, na medida em que não seria possível dar ênfase à primeira das linhas de trabalho expostas por Ferreira (1994), qual seja, a reunião de depoimentos como fontes para a complementação de dados históricos não disponíveis em documentos escritos. Formas pré-estabelecidas e contemporâneas de análise das organizações também seriam de pouca valia, na medida em que o acontecimento estudado, por singular, não só não encontrava precedentes na história do país, como também não era contemplado pelas distintas correntes dedicadas ao estudo da Administração. Por fim, apesar de ser central à historiografia contemporânea, a prevalência da estrutura, no caso estudado, ela se confundia com a messiânica figura do líder de Belo Monte tanto que a criação e o fim de Canudos estavam crucialmente ligados à trajetória e ao falecimento de Antonio Conselheiro.

Entre as fontes utilizadas, Martins (2001) lembra-se, em um primeiro momento, das documentais, dada a diversidade de relatos existentes sobre o episódio, dentre os quais o autor destaca um tipo específico - os de cronistas-testemunhas (termo cunhado pelo autor), escritos de acordo com uma perspectiva pessoal e ligada à participação de cada um na epopéia de Belo Monte. Entre esses cronistas-testemunhas estavam repórteres, religiosos, combatentes, médicos e acadêmicos de medicina e de farmácia envolvidos no embate. $\mathrm{O}$ autor destaca: 
"Se é verdadeiro que a história (que permanece) se escreve com a lenda e que a imortalidade do fato parece ser inseparável de sua idealização, a breve vida do povo do Vaza-Barris e a biografia de seu líder constituem, sem dúvida, um exemplo eloqüente dessa fatalidade.” (MARTINS, 2001, p. 127)

O autor, assim, compartilha a preocupação de Tuchman (2003), temendo o perigo da distorção ressaltado por Jacobs (2001), a partir de um fato adicional: os residentes em Belo Monte eram, em sua grande parte, analfabetos, tendo seus pertences devastados pelas forças de ocupação e, depois, submersos nas águas represadas do rio Vaza-Barris. Assim, por mais que tenham sido múltiplos os relatos sobre Canudos, eles primam pela unilateralidade, já que nascidos entre aqueles, cuja perspectiva estava ligada às forças de ocupação. A alternativa do pesquisador, dado o falecimento dos habitantes de Belo Monte, foi adotar, como fontes secundárias, depoimentos dos sobreviventes narrados por terceiros. Por outro lado, o pesquisador destaca que é numerosa a produção de documentos oficiais por parte dos vencedores da Guerra de Canudos, o que constatou a partir da consulta a acervos públicos e particulares e a órgãos governamentais em sete estados brasileiros.

Ao tratar da utilização da história oral, Martins (2001) lembra da opção que fez pela segunda linha de trabalho ressaltada por Ferreira (2004), ou seja, a que tem como aspecto central as relações entre memória e história, cujo foco é o estudo das representações. A partir da incorporação de novas fontes e ao se opor ao que chamou de "fetichismo do documento (escrito)" (MARTINS, 2001, p. 177), que apenas reconhece a historiografia baseada em fontes documentais, o autor defende a produção de signos, imbricados de ideologia, por todos os atores sociais, independentemente do tempo e do local em que vivem. Toda produção, assim, é encarada pelo autor como permeada por mensagens definidoras do imaginário social de seus emissores e repletas de significação. Justifica-se, daí, a ampliação das fontes históricas possíveis, levada em consideração pelo autor e já mencionada na seção anterior deste artigo, tais como imagens e monumentos.

Ao ampliar as fontes históricas utilizadas em sua pesquisa, Martins (2001) não só viabilizou-a, como percorreu as trilhas tornadas possíveis pela nova concepção da historiografia - a Nova História ressaltada por Curado (2001). Adicionalmente, ao optar pela utilização de documentos consagrados pelo relato tradicional da epopéia de Canudos, de acordo com a perspectiva dos vencedores da guerra, o autor buscou um contraponto por meio da expansão de suas fontes, enfatizando a multiplicidade das perspectivas de sua análise e o confronto das distintas versões, ora realçado de acordo com a linha de trabalho da história oral escolhida por ele. A estratégia consiste, ainda, em alternativa para a existência reduzida de fontes múltiplas de informação, situação decorrente não apenas da prevalência de uma versão da história associada aos vencedores da guerra, como também das distintas mazelas que acometem o Brasil - no caso, o analfabetismo dos habitantes de Canudos e a despreocupação com a memória do movimento.

A escassez de fontes é igualmente ressaltada por Pieranti (2005) em sua pesquisa, cujo objetivo é discutir as políticas públicas para radiodifusão e imprensa no Brasil a partir de 1964, utilizando a historiografia como metodologia. No levantamento bibliográfico feito pelo autor, ele destaca que alguns dos principais periódicos do campo da Administração, tais como a Revista de Administração Pública (RAP) e a Public Administration Review (PAR) jamais publicaram qualquer artigo sobre esse tema, o mesmo se repetindo nos anais dos últimos dez anos do EnANPAD. No Encontro de Administração Pública e Governança (EnAPG), também promovido pela ANPAD, foi apresentado um único artigo sobre esse tema - de autoria do próprio autor. No tocante aos depoimentos decorrentes da utilização da história oral como método de pesquisa, o autor descobriu que, entre as 400 entrevistas disponibilizadas para consulta pelo Centro de Pesquisa e Documentação de História Contemporânea do Brasil da Fundação Getulio Vargas (CPDOC/FGV), apenas uma foi feita com personalidade ligada à imprensa e à radiodifusão no âmbito do Estado, o ex-ministro das Comunicações do governo Geisel, Euclides Quandt de Oliveira.

A alternativa encontrada pelo autor foi a interdisciplinaridade, recorrendo a fontes utilizadas em estudos originados em outras áreas do conhecimento. Valeu-se, portanto, de trabalhos produzidos no âmbito da Comunicação Social, da História, das Ciências Políticas e da Sociologia. Mesmo assim, o estudo da radiodifusão e da imprensa no tocante às políticas públicas a elas dirigidas mostrou-se incomum, visto que o 
autor encontrou apenas dois trabalhos com essa abordagem. Mais que isso, o campo da Administração revelouse, de acordo com o autor, carente de um modelo apropriado para a discussão de políticas públicas voltadas às Comunicações, na medida em que os já existentes não eram preparados para levar em consideração a vinculação da área estudada com os princípios democráticos, marca do campo das Comunicações. A opção, nesse caso, foi a divisão da análise entre a dimensão técnica e tecnológica e a dimensão relativa ao conteúdo.

Outra dificuldade realçada por Pieranti (2005) foi a indisponibilidade de dados oficiais, principalmente no tocante à expansão da radiodifusão no país. Conforme ressalta o autor, a inexistência de informações oficiais ecoa o histórico de pouca transparência no setor, utilizado, não raro, como campo para a troca de favores e para o estabelecimento tácito de recompensas a grupos regionais vinculados, não raro, a interesses políticopartidários. Desatualizados, os anuários estatísticos do IBGE, por exemplo, contribuíram com dados até a década de 1980 e, mesmo assim, com interrupções na série temporal. A saída encontrada foi a utilização, como fontes históricas, de transcrições de palestras e seminários de ex-ministros das Comunicações, em que era exposto o número de emissoras existentes no país em suas gestões. Com base nas informações aí obtidas, o pesquisador elaborou um anexo ao seu trabalho que traça a evolução desse setor a partir de 1964. Outros documentos oficiais levados em consideração foram os marcos legais voltados para as Comunicações.

O contraponto ao discurso oficial foi estabelecido por trabalhos de cunho acadêmico, normalmente enfocando as Comunicações, não, sob a perspectiva das políticas públicas, mas sim, com vistas a uma discussão sobre a relação entre Estado e meios de comunicação de massa no Brasil. Pieranti (2005) destaca, ainda, a utilização de reportagens de publicações jornalísticas como fontes de pesquisa, enfatizando que, pela rotina dessa atividade, os temas de que tratam as reportagens, mormente ligados a fatos presentes, nem sempre foram debatidos pela literatura acadêmica, conforme mencionado anteriormente.

No que tange às fontes, a pesquisa de Pieranti (2005) corrobora o que anteriormente apontara Martins (2001). Face aos problemas de documentação correntes no Brasil e aos obstáculos para o acesso aos dados oficiais, o autor teve que expandir os locais em que buscou as fontes de informação para seu estudo, recorrendo, por exemplo, a bibliotecas militares e aos arquivos do Diário Oficial da União. Além disso, a pesquisa valorizou a interdisciplinaridade como estratégia possível para a sua viabilização, dada a inexistência de suficiente referencial teórico no campo da Administração - apesar de ser um tema a ele ligado, visto que foram discutidas não só políticas públicas, como também a regulação de um setor (as Comunicações) pelo Estado.

Cabe ressaltar, ainda, a ênfase dada por essa pesquisa à análise e à interpretação das estruturas, em consonância com os princípios da historiografia contemporânea. Para recontar a história das políticas públicas para as Comunicações no Brasil, Pieranti (2005) elucidou a criação e a ação de órgãos públicos, como, por exemplo, o Ministério das Comunicações e a Agência Nacional de Telecomunicações (Anatel), sendo a análise da trajetória e do comportamento de personagens específicos, complementar à das estruturas em questão.

\section{Considerações finais}

A metodologia historiográfica, tal como compreendida na contemporaneidade, permite uma abordagem diferenciada de problemas de pesquisa em estudos desenvolvidos no campo da Administração. Cabem, aqui, algumas considerações finais acerca dos princípios nos quais se fundamenta essa metodologia e, de como ela pode ser utilizada no Brasil contemporâneo.

Como frisam os autores das pesquisas utilizadas como exemplo, o investigador que opta pelo uso dessa metodologia não raro depara-se particularmente, no Brasil, com a inexistência de fontes (principalmente oficiais) apropriadas para seu estudo. São diversos os motivos: as informações podem não ter sido coletadas, estar indisponíveis ou serem pouco confiáveis. Cabe ao pesquisador, nesses casos, ou se abster de utilizá-las, ou recorrer, de alguma forma, ao improviso, entendido, aí, como a capacidade de encontrar fontes alternativas e de eventualmente consolidar dados dispersos. 
Quando é pouco difundido, no campo da Administração, o tema trabalhado pelo pesquisador, a investigação em outras áreas do conhecimento pode se tornar um recurso útil. Prevalece, assim, uma concepção de áreas integradas, não estanques, permitindo ao pesquisador a ampliação das perspectivas relacionadas ao tema em análise.

Complicador adicional para o pesquisador que faz uso da metodologia historiográfica é a fragilidade das estruturas, principalmente no âmbito público. Como a análise das estruturas é central para a historiografia contemporânea, as constantes oscilações no cenário político implicam dificuldade extra para o investigador. A história do Brasil é marcada por mudanças no cenário político e alterações no manancial legal, o que reforça a necessidade de se realizar a análise das estruturas de acordo com cada contexto específico.

É necessário frisar, pois, a singularidade como limitação aos estudos que fazem uso da metodologia historiográfica. Eventos não podem ser encarados como passíveis de completa reprodução, sendo necessária uma individualização dos mesmos, o que demanda um conhecimento da realidade não só acerca das estruturas, como também da conjuntura. O trabalho do pesquisador parte, assim, de um obrigatório conhecimento generalizado sobre a conjuntura e as estruturas em análise, cabendo a ele saber julgar e separar perspectivas e distorções constantes das fontes por ele pesquisadas. Para isso, as opções feitas - seja em relação a fontes, seja em relação às suas interpretações - devem ser claras, revelando as limitações do estudo e da metodologia utilizada. 


\section{Referências bibliográficas}

ALBERTI, Verena. História oral: a experiência do Cpdoc. Rio de Janeiro: Centro de Pesquisa e Documentação de História Contemporânea do Brasil, 1989.

BIAL, Pedro. Roberto Marinho. Rio de Janeiro: Jorge Zahar Ed., 2004.

CALDEIRA, Jorge. Mauá: Empresário do Império. São Paulo: Companhia das Letras, 1995.

CURADO, Isabela. Pesquisa Historiográfica em Administração: uma Proposta Mercadológica. In: ENCONTRO NACIONAL DA ASSOCIAÇÃO NACIONAL DOS PROGRAMAS DE PÓS-GRADUAÇÃO EM ADMINISTRAÇÃO, 25., 2001, Campinas. Anais. Campinas, SP: Anpad, 2001.

FERREIRA, Marieta de Moraes (coord.); ABREU, Alzira Alves de... (et al.). Entre-vistas: abordagens e usos da história oral. Rio de Janeiro: Editora da Fundação Getulio Vargas, 1994.

FIRAT, A. Fuat. Historiography, Scientific Method, and Exceptional Historical Events. In: Advances in Consumer Research, vol. 14, issue 1, p. $435-438,1987$.

GOMES, João Carlos Teixeira. Memória das Trevas. São Paulo: Geração Editorial, 2001.

JACOBS, Keith. Historical Perspectives and Methodologies: Their Relevance for Housing Studies? In: Housing, Theory and Society, n. 18, p. 127-135, 2001.

MAHONEY, James. Comparative-Historical Methodology. In: Annuary Review of Sociology, n. 30, p. 81-101, 2004.

MARTINS, Paulo Emilio Matos. A Reinvenção do Sertão: a estratégia organizacional de Canudos. Rio de Janeiro: Editora FGV, 2001.

MORAES NETO, Geneton. Dossiê Brasil. Rio de Janeiro: Editora Objetiva, 1997.

MORAES NETO, Geneton; SILVEIRA, Joel. Nitroglicerina Pura. Rio de Janeiro: Record, 1992.

MORAIS, Fernando. Chatô, o Rei do Brasil. São Paulo: Companhia das Letras, 1994.

PIERANTI, Octavio Penna. Políticas Públicas para Radiodifusão e Imprensa: Ação e Omissão do Estado no Brasil pós-1964. Rio de Janeiro: Escola Brasileira de Administração Pública e de Empresas/Fundação Getulio Vargas, 2005. Dissertação de Mestrado (mimeo).

PIMENTEL, Alessandra. O Método da Análise Documental: seu Uso numa Pesquisa Historiográfica. In: Cadernos de Pesquisa, Londrina, n. 114, p. 179-195, nov. 2001.

PRATA, José; BEIRÃO, Nirlando; TOMIOKA, Teiji. Sérgio Motta: o Trator em Ação. São Paulo: Geração Editorial, 1999.

SMITH, Joel. A Methodology for Twenty-First Century Sociology. In: Social Forces, The University of North Carolina Press, n. 70 (1), p. 117, September 1991.

TUCHMAN, Gaye. Historical Social Science: Methodologies, Methods, and Meanings. In: DENZIN, Norman K.; LINCOLN, Yvonna S. (org.). Strategies of Qualitative Inquiry. SAGE Publications, 2003.

VERGARA, Sylvia Constant. Método de Pesquisa em Administração. São Paulo: Atlas, 2005.

WILLIAM, Wagner. Soldado Absoluto: uma Biografia do Marechal Henrique Lott. Rio de Janeiro: Ed. Record, 2006. 